\title{
Decomposition Dynamics of Cooking-oil-soaked Paper in Media With a Low Inorganic Nitrogen Content
}

Tomasz Ciesielczuk ( $\nabla$ tciesielczuk@uni.opole.pl )

Uniwersytet Opolski https://orcid.org/0000-0003-4381-8091

Czesława Rosik-Dulewska

Polish Academy of Sciences: Polska Akademia Nauk

\section{Research Article}

Keywords: cardboard, parchment paper, cooking oil, biodegradation, low inorganic nitrogen

Posted Date: August 23rd, 2021

DOl: https://doi.org/10.21203/rs.3.rs-688895/v1

License: (c) (1) This work is licensed under a Creative Commons Attribution 4.0 International License.

Read Full License 


\section{Abstract}

Many paper-related products are in daily use all over the world. Although paper is one of the most recycled materials in the European Union, no end-of-waste criteria have been defined. Typical paper and cardboard should be recycled, but paper materials with impurities, such as water, cooking oil, sand, or plastic, are much more problematic. In particular, paper polluted with cooking oil or butter (e.g., pizza boxes) is difficult waste. Composting could be a solution, but in many municipal solid waste collection systems, this waste type is collected with the mixed waste stream. Paper and cardboard contain potentially much $\mathrm{CH}_{4}$ and, in landfills, are a source of $\mathrm{CO}_{2}$ and $\mathrm{CH}_{4}$. Incineration of these materials also causes $\mathrm{CO}_{2}$ emission. The aim of this study was to investigate the degradation of cooking-oil-polluted paper in media with a low inorganic nitrogen content. Office paper usually used for printouts was used as pre-test material. Two types of paper usually used in the kitchen were used: pizza box cardboard and parchment paper highly polluted with cooking oil. Two types of low inorganic nitrogen media were tested: mature municipal waste compost (MSWC) and leaf mold. The decrease in mass of both paper sample types was correlated with process time. All tested samples-raw cellulose materials and paper with cooking oil added-were partly or completely decomposed after 6 weeks of bioprocessing without an additional dose of inorganic nitrogen.

\section{Introduction}

Today, the total amount of paper and paper-derived products produced globally is approximately 400 million tons per year and has increased by $45 \%$ over the past 3 years. Approximately $50 \%$ of this amount consists of package and labeling paper, whereas $28 \%$ is office printing paper. The increase in paper production will probably continue over the next years [1]. Used office paper without impurities can easily be transformed into new paper of good quality, but wet paper or paper contaminated with cooking oil or other compounds cannot be recycled in this way. In many countries, used office paper that has been stored for at least 5 years will be burnt because of the low profitability of the recycling technology [2]. In 2019, the recycling rate in Europe was $72 \%$, so of the 57.5 million tons of paper produced that year, 22.36 million tons was dumped or burned, contributing to $\mathrm{CO}_{2}$ emission. Part of this paper probably had different impurities, such as water, fat, and vegetable oil, or was contained in multi-material products and, therefore, excluded from the typical recycling procedures. Common paper products, such as cardboard or office paper, contain mainly cellulose and hemicellulose, so they are $100 \%$ biodegradable [3].

Various types of organic matter contained in municipal waste or originating from the food industry may, in the absence of other contaminants, be used to create "fertilizers," which could even be reused in the organic production of arable crops. Especially interesting is the possibility of using wastepaper as organic matter for organic fertilizers, considering the problems with the disposal of cooking-oil-soaked paper. In many countries, this type of waste is placed into the mixed waste stream. This common procedure leads to the storage 
of tons of wastepaper in landfills under anaerobic conditions, ultimately giving rise to additional methane and carbon dioxide emission [4,5]. On the other hand, composting (including home composters) could be used for recycling organic matter, which is a process of the circular economy. Cellulose contained in cardboard can easily be decomposed in the presence of an inorganic nitrogen source, such as urea, saltpeter, or free ammonium, for an optimum C:N. The addition of fat, oil, or grease had a significant effect on the biological processes in a compost pile because of low oxygen circulation and an additional carbon source [6]. On the other hand, cooking oil is an easily degradable material, but access to oxygen and inorganic nitrogen ions is necessary [7]. Different materials can be processed while saving energy and organic matter, such as palm oil mill effluents, which were composted in a compost plant with good results in 40 days, but the main problem was maintaining the optimum oxygen level for microbial activity [8]. Many microbe species are able to degrade cellulose and hemicellulose. These include bacteria from the genera Clostridium, Cellulomonas, Bacillus, Thermomonospora, Ruminococcus, Bacteriodes, Erwinia, Acetovibrio, Microbispora, and Streptomyces and the fungi Trichoderma reesei, Trichoderma koningii, Penicillium funiculosum, Myrothecium verrucaria, Sporotrichum pulverulentum, and Aspergillus niger [9]. Oil-soaked paper can easily be recycled in a composting process, but with low availability of nitrogen, the process can be very slow. Low-nitrogen soils, such as sandy soil (S), mature municipal solid waste compost (MSWC), and leaf mold (LM), can be problematic media for the biodegradation of oiled or even nonoiled cellulose-containing materials. The aim of this study was to compare the degradation dynamics of different paper types heavily polluted with cooking oil in media with low inorganic nitrogen.

\section{General characteristics of vegetable oil}

Natural oils from plants are in daily use for thousands of years. They commonly occur in food and cosmetics all over the world. Chemically, natural oils are a simple combination of fatty acid esters of trihydroxy alcohol or glycerol [10]. The most common oil-rich plants are the rapeseed, the sunflower, the olive tree, the soybean, the peanut, and the palm tree. The oils of other plants (e.g., cottonseed oil) have a lower share in the natural oil market. Plant oils contain many mono- and polyunsaturated fatty acids, e.g., oleic and linoleic acids, and therefore have a relatively low melting point compared with saturated fatty acids with the same carbon content. Plant oils with a high content of saturated fatty acids are scarce. These types of oils, such as coconut oil, are solid at room temperature. During thermal treatment of vegetable oils, e.g., frying, chemical reactions take place that lead to the aging of oils. Changes in the chemical composition of vegetable oils can be fast and depend on the working conditions. Hydrolysis caused by a high water temperature, which destroys ester bonds, leads to mono- or diacylglycerol and the production of free fatty acids. Oxidation occurs under the influence of oxygen from air dissolved in oil. The oxygen attaches to the carbon atom at the $\alpha$-position of the fatty acid double bond to form a hydroperoxide. As the 
number of double bonds in fat increases, the number of sites susceptible to oxidation ( $\alpha$ positions) increases, so the rate of the oxidation process increases. Each subsequent double bond in a fatty acid increases the susceptibility to oxidation up to 10 times. Hydroperoxides are unstable and undergo oxidative polymerization (90\%) and decomposition (10\%). The decomposition products are aldehydes, ketones, and aldehyde ketones. These compounds are volatile and impart a rancid smell to the fat.

Thermal polymerization is a process that takes place in the deeper layers of oil, where, because of the reduced solubility of oxygen at high temperatures, the access of fat molecules to oxygen is limited. Therefore, the cause of the polymerization of fats is prolonged heating at a high temperature. The products of this process are simple and consist of cyclic polymers, often with a high molecular weight. Their presence causes an increase in viscosity and a darkening of the oil.

\section{Biodegradation of vegetable oil}

Biodegradation is a multi-stage microbial process that converts organic compounds into simple forms in which basic elements such as carbon, nitrogen, and oxygen are present mostly in inorganic forms. All degradation reactions are catalyzed by enzymes and do not exist in sterile environments. Additionally, some of the substrate's organic compounds are converted into large humic substances, which form an important part of the humus layer.

A soil or compost environment is rich in many microbial groups, such as bacteria, fungi, and yeasts, but microbial colonies need a few days to adapt to a new substrate [11]. Many microorganisms have the ability to secrete extracellular lipases responsible for lipid biodegradation [12]. On the other hand, the $\mathrm{pH}$ value has an important role in biodegradation processes. Moisture, nitrogen, phosphorus, and other elements are necessary for biodegradation. Vegetable oils can be degraded both under aerobic and under anaerobic conditions, but the aerobic process is more effective. First, microbial enzymes crack the ester bond between glycerol and fatty acids. A wide range of microorganisms produce specific enzymes, such as esterases and lipases, that can cleavage ester bonds. Next, b-oxidation is the general process by which the oil components are fully converted. The complete process (with a conversion rate of 70-100\%) takes about 28 days under test conditions $[10,12]$.

\section{Materials And Methods}

\section{Pre-test}

A one-month pre-test was carried out with sandy soil and shredded dry office paper (OP). Samples of 1, 2, and $3 \mathrm{~g}$ of paper chips (from a small office paper shredder) were placed 
into plastic containers filled with $240 \mathrm{~g}$ of sandy soil. Rainwater was used for watering the test containers. The water content changed during the experiment because of evaporation and watering. The temperature during the test was $20^{\circ} \mathrm{C}$. After one month, the mass of the paper and the inorganic nitrogen consumption were measured.

\section{Leaf mold test}

A one-month pre-test was carried out with leaf mold and small sheets of cardboard from a pizza box (PB). The details of the preparation of the samples are described in the section "Compost test." About $3.1 \mathrm{~g}$ of dry samples and $4.5 \mathrm{~g}$ of oiled samples cut into small pieces $(5 \times 7 \mathrm{~cm}$ ) were placed vertically and processed in plastic containers filled with leaf mold (PB:LM = 1:100 w/v). Leaf mold (2-3 years old) was obtained from a local dumping site for tree leaves, where the leaves from a municipal park were deposited. Rainwater collected from a steel roof was used for watering the test containers. The test temperature was $20 \pm$

$2{ }^{\circ} \mathrm{C}$. The water content was controlled by weight loss and filled up to the initial mass every week. After 2 and 4 weeks, the mass of the cardboard and the inorganic nitrogen consumption were measured.

\section{Compost test}

A six-week test with prepared parchment paper (PP; baking sheets) was conducted. Waste PP paper was used as a simulation of baking paper after the baking of a cake. The tested PP (baking sheets) was double-sided covered with silicone. These samples were divided into two types: dry (D) samples and oiled (O) samples. Sunflower oil from a local market was used for sample preparation. D samples were dried at $25^{\circ} \mathrm{C}$ for 24 hours prior to use. $\mathrm{O}$ samples were soaked in sunflower oil for 24 hours prior to use. One type of medium was tested: mature municipal solid waste compost (MSWC). This material was made of a mixed waste stream. Compost was obtained from a municipal compost plant and sieved through a $2 \mathrm{~mm}$ sieve for the removal of impurities. An additional maturation process of 1 year was carried out for a complete conversion of the waste biomass. The experiments were conducted in plastic pots. To make the decomposition process more difficult, the original PP samples were folded 4 times (thus obtaining 8 layers) to a size of about $2 \times 3 \mathrm{~cm}$, pressed down, and placed into pots filled with MSWC in a PP:MSWC ratio of 1:125 w/v. Natural rainwater was used for watering the test containers during the experiment. Rainwater was stored in open plastic containers prior to use.

Basic parameters were measured with standard methods: $\mathrm{pH}$ and electrical conductivity (EC) using the potentiometric approach, according to the soil analysis procedures. Organic matter was measured as a "loss of ignition" at $600{ }^{\circ} \mathrm{C}$ for 3 hours. Organic carbon was measured with a Carl Zeiss Jena $\mathrm{C} / \mathrm{N}$ analyzer. Inorganic nitrogen (IN = ammonium + nitrates) was analyzed with spectrophotometric methods after 1 hour of shaking in $1 \%$ 
$\mathrm{K}_{2} \mathrm{SO}_{4}$ at room temperature. Solid medium samples for IN analysis were divided into two sample types: (1) material from the paper sample area and (2) material from the external parts of the container as a control. Total phosphorus was measured with the titration method. The content of $\mathrm{Ca}, \mathrm{K}$, and $\mathrm{Na}$ was measured by the Flame Emission Spectrometry method with a BWB-XP photometer. Sandy soil, leaf mold, and compost samples were collected directly from the paper sample area. The decomposition process was carried out in plastic containers containing the tested media (MSWC and LM) with cardboard or parchment paper added.

\section{Results And Discussion}

The tested cellulose-containing materials had a different composition (Table 1). Except in density, differences were observed in all analyzed parameters. Especially important for the susceptibility to microbial decomposition is the $\mathrm{C}: \mathrm{N}$ ratio. The highest value in the OP samples could

Table 1. Characteristics of the tested paper materials (SD in brackets)

\begin{tabular}{|llll|}
\hline & OP & PB & PP \\
\hline Density $\left[\mathrm{g} / \mathrm{m}^{2}\right]$ & 79.4 & 387 & 38.5 \\
\hline Organic matter [\%] & $78.95(0.038)$ & $83.31(0.003)$ & $97.56(0.084)$ \\
\hline TOC $[\mathrm{g} / \mathrm{kg}]$ & $289.0(0.55)$ & $295.7(6.9)$ & $333.9(3.4)$ \\
\hline Total $\mathrm{N}[\mathrm{g} / \mathrm{kg}]$ & 2.12 & 5.35 & 3.76 \\
$\mathrm{C}: \mathrm{N}$ ratio & 136 & 55 & 89 \\
$\mathrm{P}_{2} \mathrm{O}_{5}[\mathrm{~g} / \mathrm{kg}]$ & 3.91 & 6.93 & 7.35 \\
$\mathrm{CaO}[\mathrm{g} / \mathrm{kg}]$ & $92.3(0.6)$ & $67.3(0.4)$ & $0.28(0.01)$ \\
\hline $\mathrm{K}_{2} \mathrm{O}[\mathrm{g} / \mathrm{kg}]$ & $0.12(0.02)$ & $0.24(0.003)$ & $0.16(0.03)$ \\
$\mathrm{Na}_{2} \mathrm{O}[\mathrm{g} / \mathrm{kg}]$ & $0.98(0.01)$ & $0.84(0.004)$ & $1.13(0.01)$ \\
\hline
\end{tabular}

have hampered the biodegradation process because of a low source of inorganic nitrogen, especially in the S medium, where the IN content was very low (Table 2). The highest organic matter content in the PP material is interesting because it was double-sided covered with silicone, which should increase the ash content. The solid media prepared as decomposition environments had a different composition. The $\mathrm{pH}$ value was close to neutral for MSWC and LM and was slightly lower for the S samples, which is optimal for the intensity of the microbial processes. The different EC values were typical, especially in MSWC, in which many waste substances were treated. Resources of inorganic nitrogen were important because of the short test time period and the problematic decomposition of organic matter with the release of 
nitrogen. The lowest inorganic N content was found in S, and the highest in MSWC (Table 2). The low amount of all nutrients in $\mathrm{S}$ can be problematic for microbial communities, so the decomposition process of cellulose materials will be slow. The tested solid media S, MSWC, and LM had a typical composition [13].

Table 2. Characteristics of mediums with low inorganic nitrogen.

\begin{tabular}{|llll|}
\hline & $\mathrm{S}$ & $\mathrm{MSWC}$ & $\mathrm{LM}$ \\
\hline $\mathrm{pH}\left(\mathrm{H}_{2} \mathrm{O}\right)$ & $6.52-6.61$ & $7.89-8.02$ & $7.46-7.47$ \\
\hline $\mathrm{pH}(\mathrm{KCl})$ & $5.85-5.90$ & $7.12-7.19$ & $6.93-6.97$ \\
\hline $\mathrm{EC}[\mathrm{mS} / \mathrm{cm}]$ & $158-166$ & $2870-2995$ & $853-941$ \\
\hline $\mathrm{OM}[\%]$ & $2.58(0.17)$ & $48.16(4.18)$ & $60.71(4.66)$ \\
\hline $\mathrm{TOC}[\%]$ & $0.45(0.03)$ & $21.9(2.6)$ & $23.4(1.2)$ \\
\hline Total nitrogen $[\%]$ & 0.021 & 0.95 & 1.04 \\
\hline $\mathrm{C}: \mathrm{N}$ & 21.4 & 26.2 & 22.5 \\
\hline $\mathrm{NH}_{4}{ }^{+}[\mathrm{g} / \mathrm{kg}]$ & 0.023 & 0.682 & 0.141 \\
\hline $\mathrm{NO}_{3}{ }^{-}[\mathrm{g} / \mathrm{kg}]$ & 0.030 & 0.876 & 0.459 \\
\hline $\mathrm{P}_{2} \mathrm{O}_{5}{ }^{[\mathrm{g} / \mathrm{kg} \mathrm{dm}]}$ & 0.16 & 1.36 & 4.62 \\
\hline $\mathrm{CaO}[\mathrm{g} / \mathrm{kg}]$ & 4.09 & 62.29 & 15.99 \\
\hline $\mathrm{K}_{2} \mathrm{O}[\mathrm{g} / \mathrm{kg}]$ & 0.135 & 3.798 & 1.781 \\
\hline $\mathrm{Na}_{2} \mathrm{O}[\mathrm{g} / \mathrm{kg}]$ & 0.209 & 5.270 & 0.157 \\
\hline
\end{tabular}

A particularly interesting material was MSWC because of its high content of mesophilic organisms, which remain present a long time after composting processes. However, also for long storage with medium water content, the organic matter was slowly mineralized with the release of mineral biogens (Fig. 1).

\section{Results of the pre-test}

A small amount of the OP samples was decomposed because of the low content of nitrogen and other elements (Table 3). Despite the large contact area with the solid medium, the decomposition was weak.

Table 3. Paper samples after 30 days of decomposition. 


\begin{tabular}{|llll|}
\hline & $1 \mathrm{~g}$ & $2 \mathrm{~g}$ & $3 \mathrm{~g}$ \\
\hline \% of degradation & 28.1 & 19.5 & 12.5 \\
\hline $\mathrm{NH} 4+$ budget $[\mathrm{g} / \mathrm{kg}]$ & -0.072 & -0.090 & -0.114 \\
\hline NO3- budget $[\mathrm{g} / \mathrm{kg}]$ & -0.028 & -0.036 & -0.041 \\
\hline
\end{tabular}

The best results were obtained for the $1 \mathrm{~g}$ OP samples. Office paper material is very susceptible to decomposition in soil or other media, but the best C:N ratio is 25-30:1, as in a fresh compost pile. In the presence of compost, complete degradation of cellulose materials was obtained after 21 days, but to ensure a good C:N ratio, a dose of chicken manure with a high nitrogen content was added [14]. The C:N ratio in sandy oil is suitable for microbial communities, but in the OP samples, the conditions for decomposition were bad, also because of the low content of nutrients, particularly inorganic nitrogen. In addition to a good C:N ratio, the presence of microorganisms and the availability of nitrogen and other elements are optimal conditions for the dynamics of the biodegradation process. The visual changes in the OP samples are shown in Figs. 1 and 2. The results obtained with the decomposition of the office paper samples in a relatively short time could probably have been better with a stable water content. The soil humidity varied in a wide range from 15 to $49 \mathrm{~g}$ of water per pot. Differences in soil humidity can be an important factor for microbial communities and the final grade of paper deterioration [15].

\section{Results of the leaf mold test}

The second test with PB samples incubated in LM for 6 weeks showed a great susceptibility of this material to microbial decomposition (Table 4). Both sample types (D and 0 ) were

Table 4. Pizza box cardboard samples decomposition

\begin{tabular}{|llll|}
\hline & 2 weeks & 4 weeks & 6 weeks \\
\hline D samples degradation [\%] & 12,29 & 34,21 & 41,73 \\
\hline O samples degradation [\%] & 16,71 & 35,37 & 43,35 \\
\hline D samples NH4+ budget [g/kg] & $-0,027$ & $-0,053$ & $-0,082$ \\
\hline D samples NO3- budget [g/kg] & $-0,088$ & $-0,136$ & $-0,149$ \\
\hline O samples NH4+ budget [g/kg] & $-0,061$ & $-0,086$ & $-0,127$ \\
\hline O samples NO3- budget [g/kg] & $-0,062$ & $-0,096$ & $-0,132$ \\
\hline Veg. oil lost [\%] & 66,5 & 70,0 & 72,5 \\
\hline
\end{tabular}

covered with microbial organisms, and after 6 weeks of incubation, only $58.3 \%$ and $56.6 \%$ of the original samples were left, respectively. The oiled surfaces were relatively big, and the direct contact with LM led to a quick decomposition with almost the same results as for the $D$ samples. Oxygen is 5 times more 
soluble in sunflower oil than in water, so this phenomenon increases the degradation speed in sunflower oil [16]. Moreover, used sunflower oil has a high content of linoleic acids (over 60\%) and oleic acids (over $20 \%$, which are prone to oxidation [17]. Fungi play a central role in the decomposition of plant litter, so LM is a special material. These organisms produce a suite of extracellular enzymes responsible for the decomposition of lignin, cellulose, and other components in litter. The action of fungi is slow, but they can grow in environments with a low content of inorganic nutrients. Despite the relatively high density of PB, the degradation process was successful in the presence of a low content of inorganic nitrogen [18]. Leaf mold is rich in multiple fungi communities, so vegetable oil did not slow down the decomposition of paper [19].

The samples showed a relatively quick decrease in oil content, a high microbial activity, and a good transformation rate (over $40 \%$ ) just after 14 days of incubation. Similar results were obtained in composting experiments with cardboard, fresh grass, and sewage sludge, but the nitrogen amount was high, and the decomposition was aided with eight dig-overs, which were performed every 30 days of the process [20].

\section{Results of the compost test}

Although the PP samples were folded and pressed down, the decomposition of both sample types ( $D$ and 0 ) in compost medium was fast. Many eubacteria and fungi and some anaerobic protozoa and slime molds are able to degrade cellulose, but better conditions are present in fresh compost because mature compost is likely to slowly release inorganic nitrogen [21,22]. Enzymatic reactions will be different in the sample area: aerobic conditions on the external surfaces $(2$ by $6 \mathrm{~cm})$, where there is direct contact with the compost medium, and semi-anaerobic conditions inside the sample, where only a layer of cooking oil is present between the PP layers. Complete removal of air from the PP samples is not possible because of the high solubility of oxygen in sunflower oil. As a result of these facts, the speed of PP degradation differs within a sample, especially in the first 7-10 days of incubation. Inside a PP sample, the degradation is slow because of a low nutrient concentration. The internal parts of the folded sample will be degraded by the end of the experiment. The conditions for degradation are much better on the external surface of the sample, which has direct contact with the compost and so has access to water and oxygen. The worst conditions are inside the sample, also because of the low content of mineral nitrogen. Therefore, the semi-anaerobic microbial communities need more time for growth between the oiled PP surfaces. In normal waste processing, the PP sheet is partly crumpled and disposed of with the mixed waste stream on a dumping site. Despite the anaerobic conditions inside a waste pile, the decomposition could be fast because of a high nitrogen content. The PP mass is transformed into $\mathrm{CH}_{4}$ and $\mathrm{CO}_{2}$, which are some of the greenhouse gases emitted from a dumping site. Methane itself can be used as a fuel source but if not captured it has a global warming potential 21 times stronger than $\mathrm{CO}_{2}$.

Raw PP samples and PP samples after 5 weeks of incubation are shown in Fig. 4. 
The oiled samples were partly decomposed. The cooking oil was more than $80 \%$ degraded, and many free paper fibers could be seen. Despite the lack of a thermophilic stage, which is present during a typical composting process, the decomposition dynamics were fast. In comparison with the high temperature during the first composting stage, the low temperature in the experiment was a negative factor for the growth of mesophilic microbial communities and for the speed of the chemical reactions [23]. After 5 weeks, the $D$ samples were almost totally decomposed, in agreement with a study using fresh compost [18]. The samples were very delicate and fell apart at the touch of a finger. After 6 weeks, it was complicated to extract a PP sample from the compost medium, but it was still possible to recognize the sample because of the black carbon-looking material. It was not possible to obtain clean parts of PP, as the rest of the samples fell apart during the removal of compost particles. The general characteristics of the decomposition process are shown in Figs. 5 and 6.

Composting conditions (with a high-temperature period) are suitable for paper decomposition, but also in mature "cold" material, the speed of the process is sufficient. In compost maturation processes, white-rot fungi have been isolated, and they may play an important role in the degradation of paper [22]. Mature compost is rich in nitrates and non-hydrolyzable $\mathrm{N}$ forms. The production of non-hydrolyzable $\mathrm{N}$ forms ensures that the end product of composting is less susceptible to biological decomposition and $\mathrm{N}$ losses [21]. Under these conditions, mature compost provides much more inorganic nitrogen for microbial communities than fresh compost, in which proteinaceous materials are some of the first materials to be used by microbes. Oiled PP samples are complicated materials for degradation, but the multiple communities of microbes that are present in compost medium caused a mass loss of over $70 \%$ after 6 weeks, thus showing highly active decomposition dynamics in comparison with the decomposition of leaves by pure fungi cultures [19].

The main difference in degradation between both series of samples is the presence of cooking oil. This presence leads to a two-stage process in the case of the 0 samples. The first stage is the degradation of the oil layer, and the second stage is the decomposition of cellulose. Both substances are fully biodegradable, but the access of specific microorganisms to paper or cardboard is blocked by the vegetable oil layer, which must be removed first. The internal layers are insulated from water and inorganic nitrogen, and they were less decomposed than the external part of the sample.

The 0 samples were rich in organic substances, a condition that accelerates microbial activity during the composting process. Although it has a low water solubility, cooking oil is a good carbon source for compost microflora, and it can be easily decomposed in the first month of the composting process if water is available [24]. In used MSWC, the total nitrogen content was high because of the high organic matter share but especially because of the easily available inorganic nitrogen (only $16.4 \%$ of the total nitrogen content), which accelerates the conversion of lignin and cellulose. Fresh compost is much more suitable, and paper decomposition takes about 20 days or less [18]. Many fungi species that are able to decompose leaves are mesophilic organisms and grow at 20-25 ${ }^{\circ} \mathrm{C}$ [19]. The results obtained under these conditions showed a quick mass loss as a result of cellulose decomposition in the presence of a low content of inorganic nitrogen. A special place is the solid medium area that stays in direct contact with 
the PB or PP sample. This microenvironment is quickly depleted of inorganic nitrogen resources, and renewal is not possible except by organic matter decomposition, which is slow because of a lack of nitrogen. The second source of nitrogen could be rainwater, but in this case, the concentrations of nitrogen ions are also low [25]. The third source of nitrogen is the air present in the pores of a solid medium. Nitrogen is bound by facultative anaerobic nitrogen-fixing cellulose-degrading bacteria [26]. Both sources provide microbes with nitrogen because of the low amounts released during the degradation of compounds in the solid media and samples.

Usually, during waste disposal, PP is not many times folded but only slightly crushed, which ensures good access of the PP surface to oxygen and microflora. Thus, slightly crushing PP instead of folding it could be a good procedure in waste disposal. Oil-soaked papers, such as PB or PP, should be added to the biodegradable waste stream. The compost from big municipal compost plants is not of top quality, but in many cases, it may be used in agriculture for the prevention of soil erosion and desertification [20,23]. On the basis of the results of this study, it is recommended to divide PB into two parts: (1) dry material for paper recycling and (2) material polluted by cooking oil for composting. Furthermore, PP (baking sheets) should be stored with biodegradable waste. The way to obtain low $\mathrm{CO}_{2}$ emission and organic matter recycling is to dump the polluted paper in biodegradable waste or even in biomass with a low inorganic nitrogen content.

\section{Conclusion}

The results of the experiments showed that vegetable-oil-soaked paper can be quickly decomposed. The low amount of inorganic nitrogen did not inhibit decomposition. Both tested oil-soaked materials-pizza box cardboard and parchment paper-are easily biodegradable. Even with a high content of vegetable oil, the decomposition process is fast, and there are no further problems with toxic by-products. The test period (6 weeks) was sufficient for dry PP decomposition and a high degradation rate in the other types of samples. The rules for selective waste collection must be changed. Oiled paper, such as pizza box cardboard, should be divided into two parts: (1) the dry (upper) part, which should be collected with the paper waste stream, and (2) the bottom part (with oil), which should be placed in a biodegradable bin but not in a mixed waste bin. A decomposition time of 6 weeks for paper means that it does not pose a threat to the environment and that it can be a valuable source of organic matter for compost plants.

\section{References}

1. Bekiroğlu S., Elmas G.M., Yagshiyev Y. Contribution to Sustainability and the National Economy Through Recycling Waste Paper from Istanbul's Hotels in Turkey. BioResources 12(4), 6924-6955 (2017)

2. Karahan, S.: Investigation of Recycling Possibilities of Stacked Waste Office Paper for at Least Five Years. GUSTIJ DOI: 10.17714/gumusfenbil.606061 (2020) 
3. Agarwal, G., Liu, G., Lattimer G.: Pyrolysis and Oxidation of Cardboard. DOI: 10.3801/IAFSS.FSS.11124 (2014)

4. Micales, J.A., \& Skog, K.E.: The Decomposition of Forest Products in Landfills. International Biodeterioration \& Biodegradation 39, 2-3 145-158 (1997)

5. Li, Z., Wrenn, B.A., Venosa, A.D.: Anaerobic biodegradation of vegetable oil and its metabolic intermediates in oil-enriched freshwater sediments Biodegradation 16, 341-352 (2005)

6. Al-Mutairi, N.: Co-composting of manure with fat, oil, and grease: Microbial fingerprinting and phytotoxicity evaluation. Can. J. Civ. Eng. (2009) doi:10.1139/L08-117

7. Saletes, S., Siregar, F.A., Caliman, J.P., Liwang, T. Ligno-Cellulose Composting: Case Study on Monitoring Oil Palm Residuals. Compost Science \& Utilization, 12(4),372-382 (2004).

8. Wan Razali, W.A., Baharuddin, A.S., Talib, A.T., Sulaiman, A., Naim, M.N., Hassan, M.A., Shirai, Y.: Degradation of oil palm empty fruit bunches (OPEFB) fibre during composting process using invessel composter. Bioresources 7(4) 4786-4805 (2012)

9. Wołczyński, M., Janosz-Rajczyk M.: Influence of Initial Alkalinity of Lignocellulosic Waste on Their Enzymatic Degradation DOI: 10.2478/aep-2014-0019 ; ISSN 2083-4772 ; elSSN 2083-4810 (2014)

10. Aluyor, E.O., Obahiagbon, K.O., Ori-jesu M. Biodegradation of vegetable oils: A review. Scientific Research and Essay 4(6), 543-54 (2009)

11. Kaakinen, J., Vahaoja, P., Kuokkanen, T., Roppola, K.: Studies on the Effects of Certain Soil Properties on the Biodegradation of Oils Determined by the Manometric Respirometric Method. J. Automated Methods and Management in Chemistry doi:10.1155/2007/34601 (2007)

12. Salihu, I., Mohd, Y.S., Nur, A.Y., Siti, A.A. 2018. Microbial degradation of vegetable oils: a review. Malaysian Journal of Biochemistry and Molecular Biology. 3, 45 - 55 (2018)

13. Ghehsareh, M.G., Khosh-Khui, M., Nazari, F.: Comparison of Municipal Solid Waste Compost, Vermicompost and Leaf Mold on Growth and Development of Cineraria (Pericallis $\times$ hybrida 'Star Wars'). Journal of Applied Biological Sciences 5 (3), 55-58 (2011)

14. Ahmed, S., Hall, A. M., Ahmed, S. F.: Proceedings of the 5th International Conference on Natural Sciences and Technology (ICNST'18) March 30 - 31, Asian University for Women, Chittagong, Bangladesh (2018)

15. Bogaard J., Whitmore P.M.: Explorations of the role of humidity fluctuations in the deterioration of paper, Studies in Conservation. DOI: 10.1179/sic.2002.47.s3.003 (2002)

16. Cuvelier, M.E., Soto, P., Courtois, F., Broyart, B., Bonazzi, C.: Oxygen solubility measured in aqueous or oily media by a method using a non-invasive sensor. https://doi.org/10.1016/j.foodcont.2016.11.008 (2017)

17. Cichosz, G., Czeczot, H.: Oxidative stability of edible fats - consequences to human health Bromat. Chem. Toksykol. XLIV, 1, 50-60 (2011)

18. Nowińska, A., Baranowska, J., Malinowski, M.: The analysis of biodegradation process of selected paper packaging waste. Infrastructure And Ecology Of Rural 
Areas DOI: https://doi.org/10.14597/INFRAEC0.2019.3.1.018 (2019)

19. Osono, T.: Functional diversity of ligninolytic fungi associated with leaf litter decomposition. Ecological Research. DOI: 10.1111/1440-1703.12063 (2019)

20. Balada I., Altmann V., Šařec P.: Material waste paper recycling for the production of substrates and briquettes. Agronomy Research 14(3), 661-671 (2016)

21. Pare, T. Dinel, H. Schnitzer,M., Dumontet, S. Transformations of carbon and nitrogen during composting of animal manure and shredded paper. Biol Fertil Soils. 26 (1), 173-178 (1998)

22. Perez, J., Munoz-Dorado, J., Rubia, T. d.I. Martınez, J. Biodegradation and biological treatments of cellulose, hemicellulose and lignin: An overview. International Microbiology. 5 (2), 53-63 (2002)

23. Franica, M., Grzeja, K., Paszula, S.: Evaluation of quality parameters of selected composts. Archives of Waste Management and Environmental Protection. 20(1), 21-32 (2018)

24. Ozimek, A., Kopeć M. Assessment of biological activity of biomass at different stages of composting process with use of the oxitop control measurement system. Acta Agrophysica, 19(2), 379-390, (2012)

25. Ciesielczuk T., Rosik-Dulewska Cz., Kochanowska K. The influence of biomass ash on the migration of heavy metals in the flooded soil profile - model experiment. DOI: 10.2478/aep-2014-0034 (2014)

26. Smirnova I. E. and Saubenova M. G. Use of Cellulose-Degrading Nitrogen-Fixing Bacteria in the Enrichment of Roughage with Protein. Applied Biochemistry and Microbiology. 37(1), 76-79 (2001)

\section{Figures}
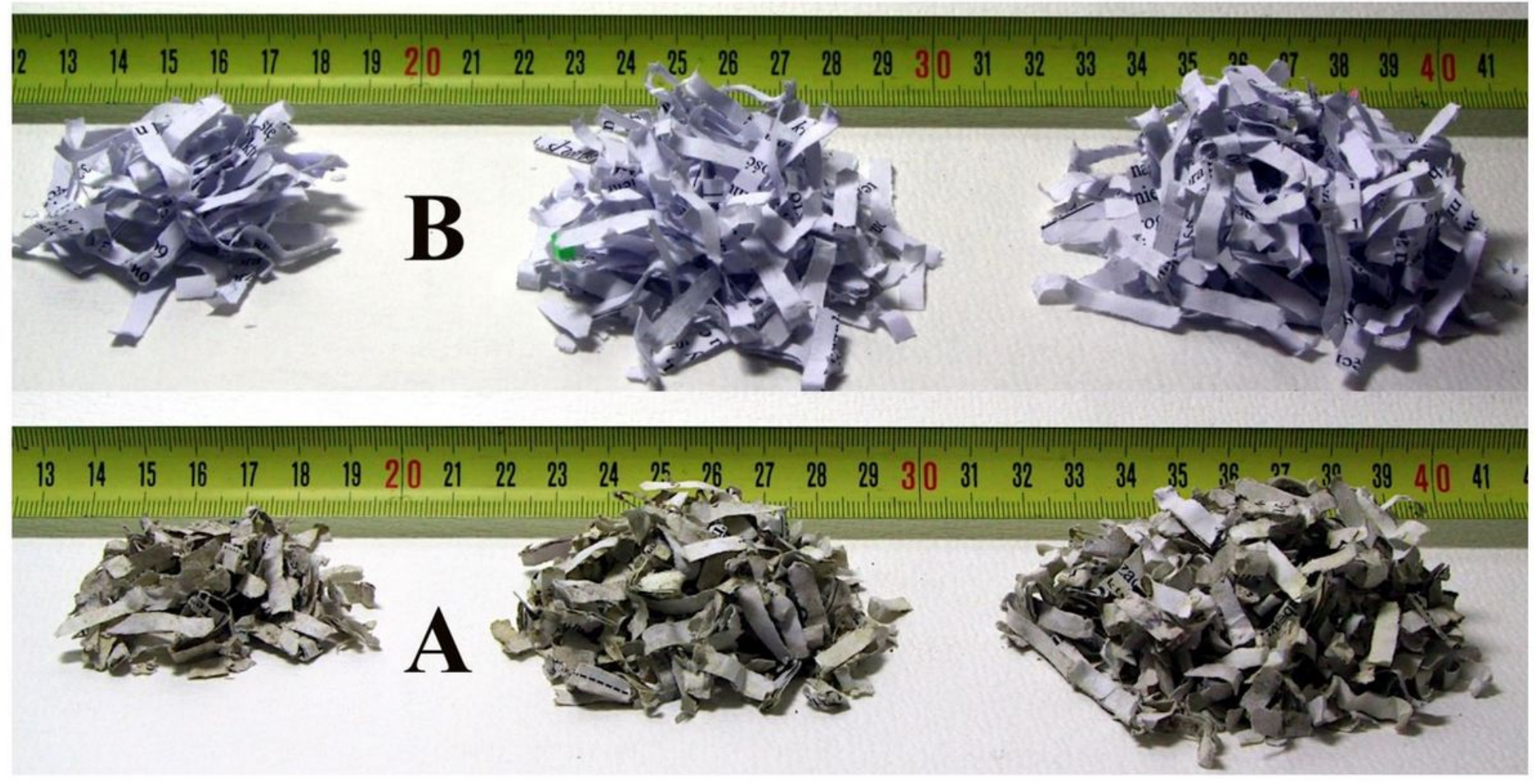
OP samples before (B) and after (A) the experiment in sandy soil.

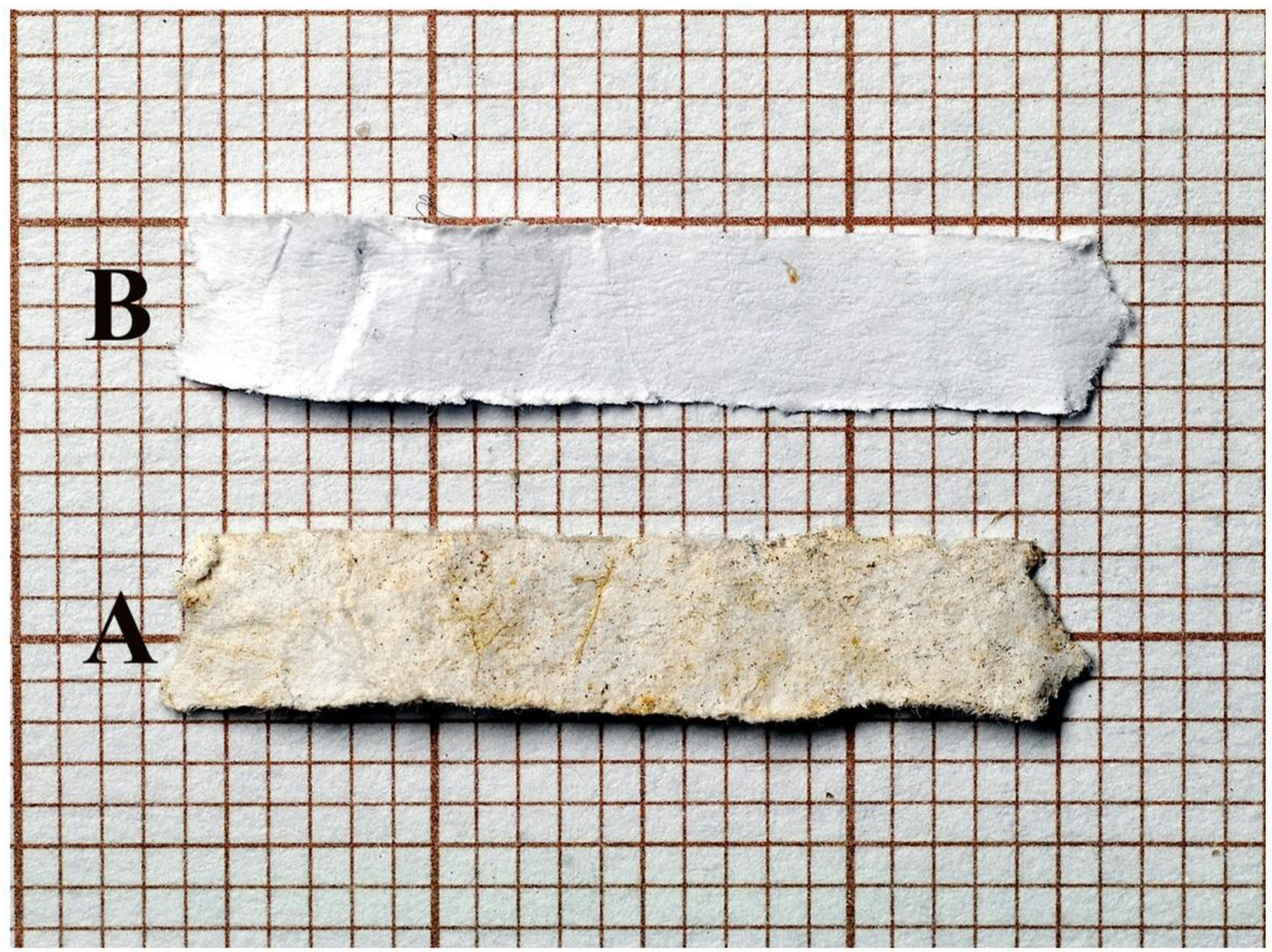

Figure 2

Close up of a paper sample, before and after the experiment. 

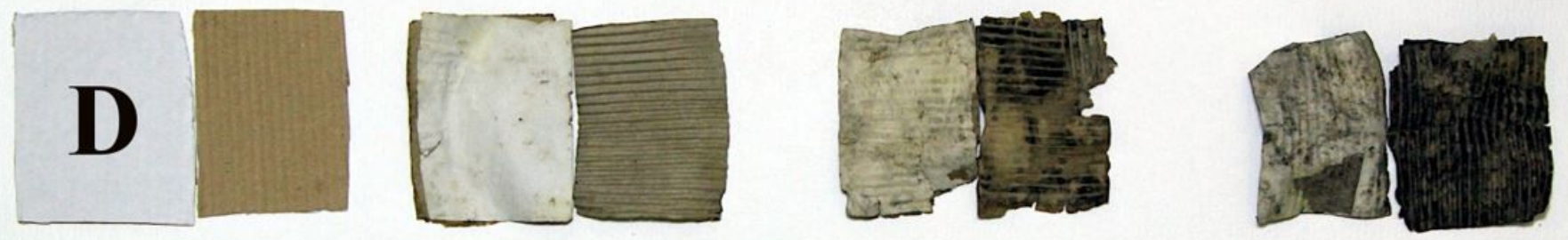

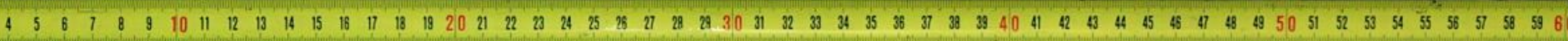
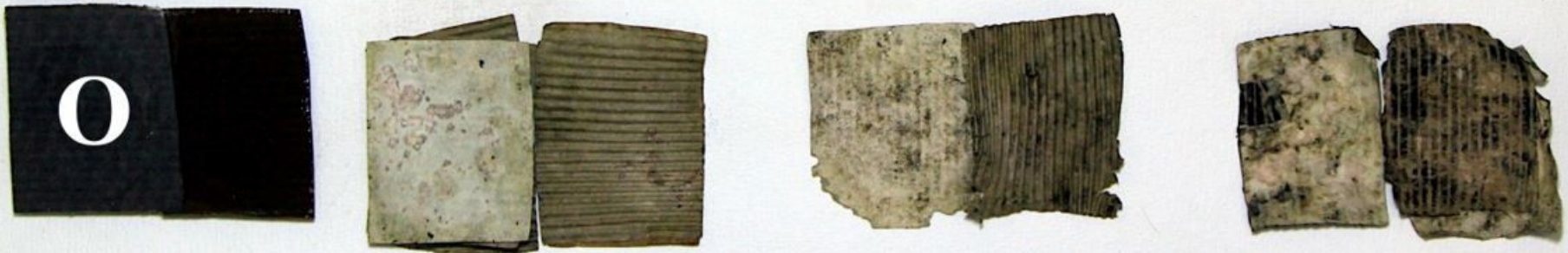

Figure 3

Dry (D) and oiled (O) PB samples after 0, 2, 4, and 6 weeks in leaf mold. The black color of the original 0 sample (left, bottom) is caused by the high oil content.

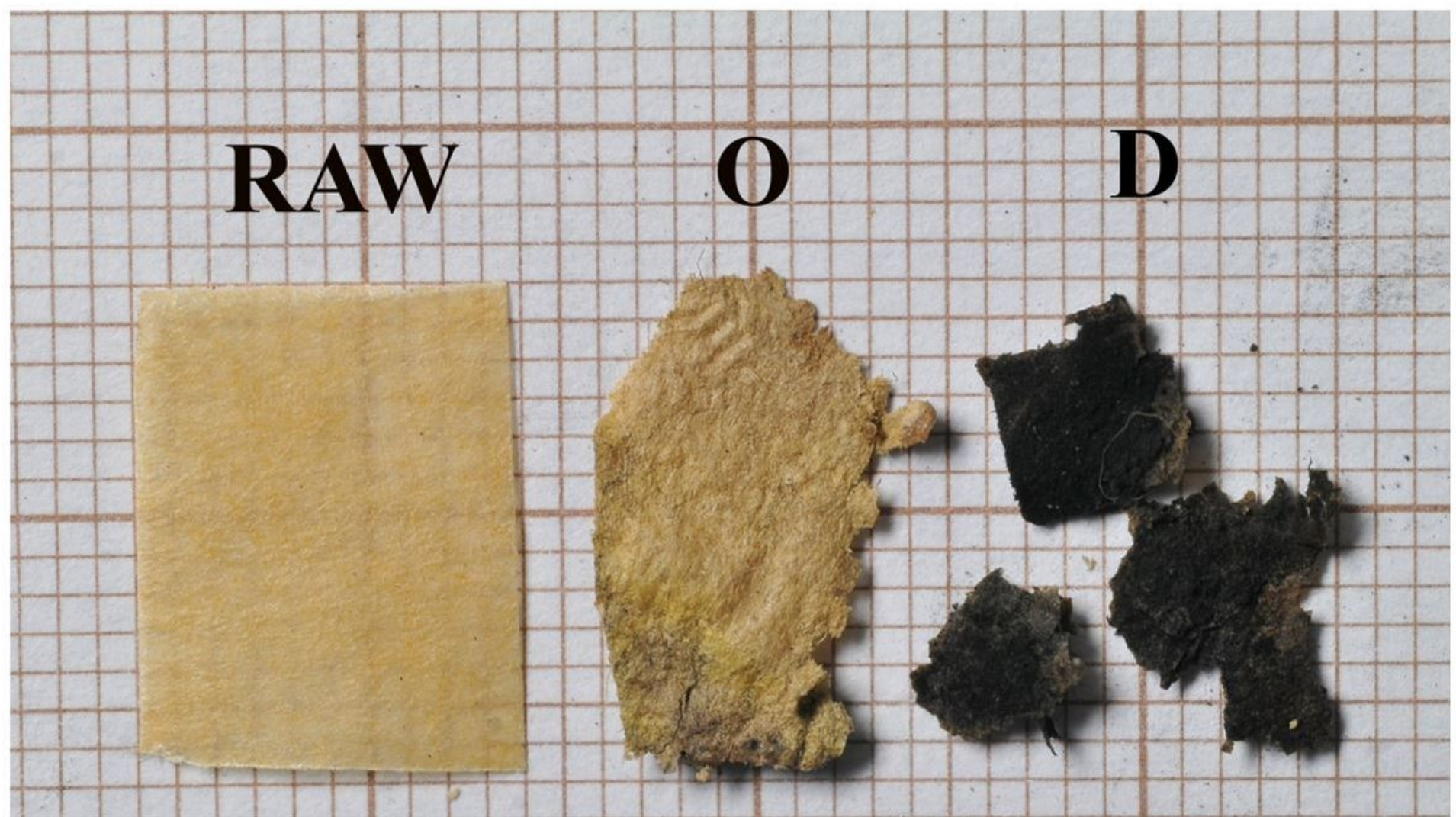

Figure 4 
Samples of PP: raw (before the experiment) and after 5 weeks of incubation, both oiled (0) and non-oiled (D).

$$
\diamond \quad D \quad \square \quad O \longrightarrow \text { Log. (D) - - - Log. (O) }
$$

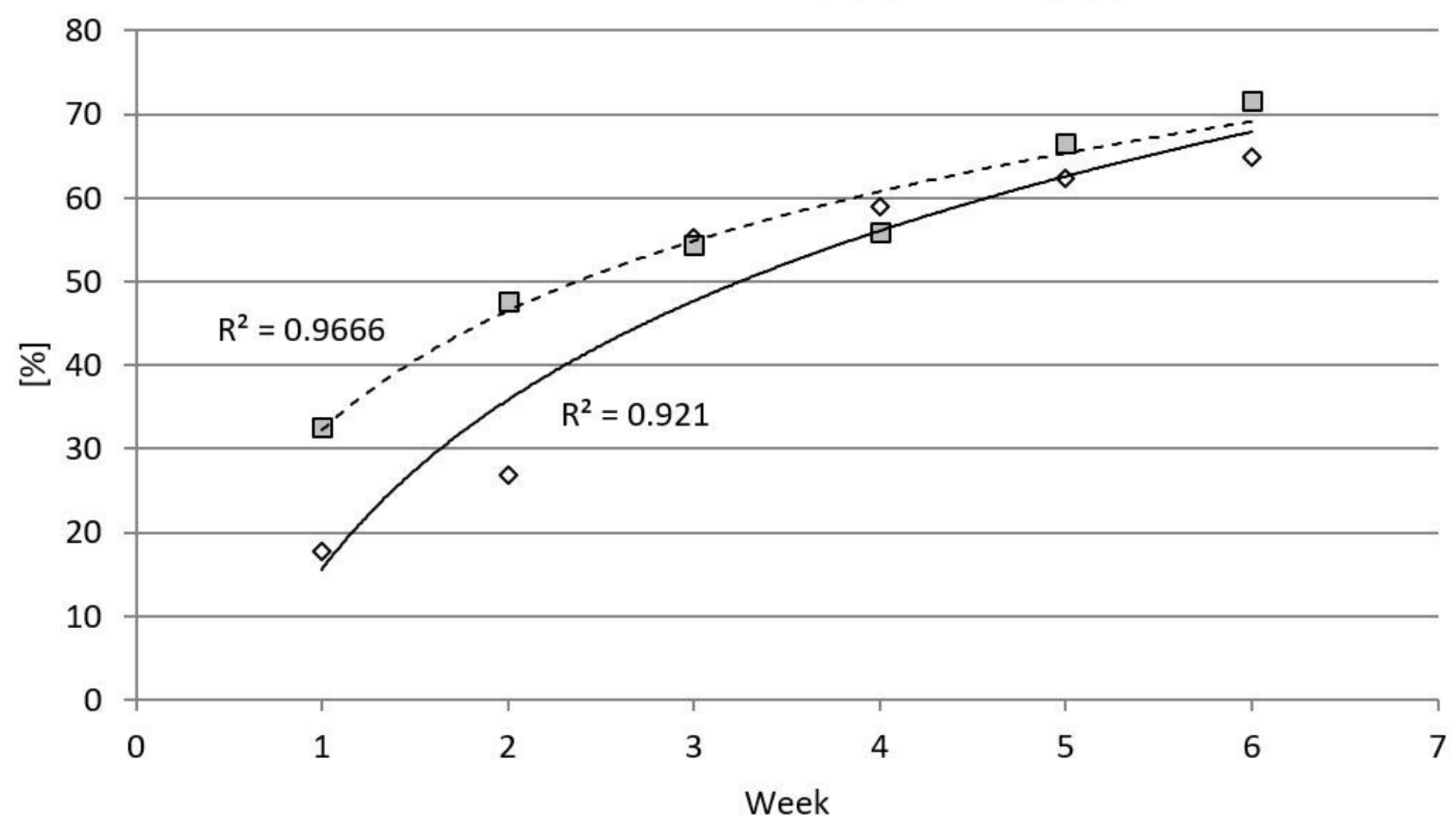

\section{Figure 5}

Weight dynamics in the PP samples (dry and oiled). 


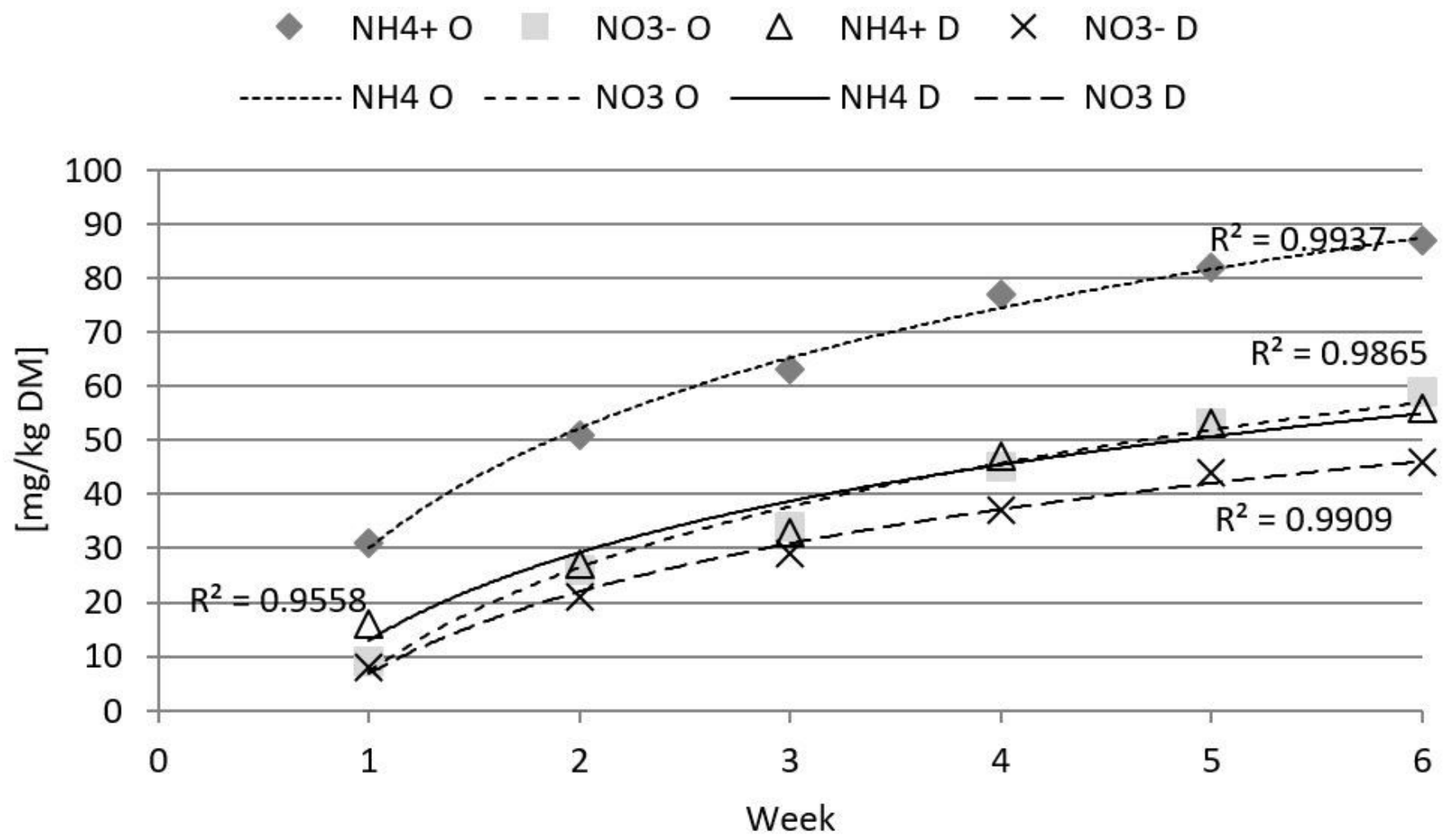

Figure 6

Inorganic nitrogen budget of PP samples (dry and oiled).

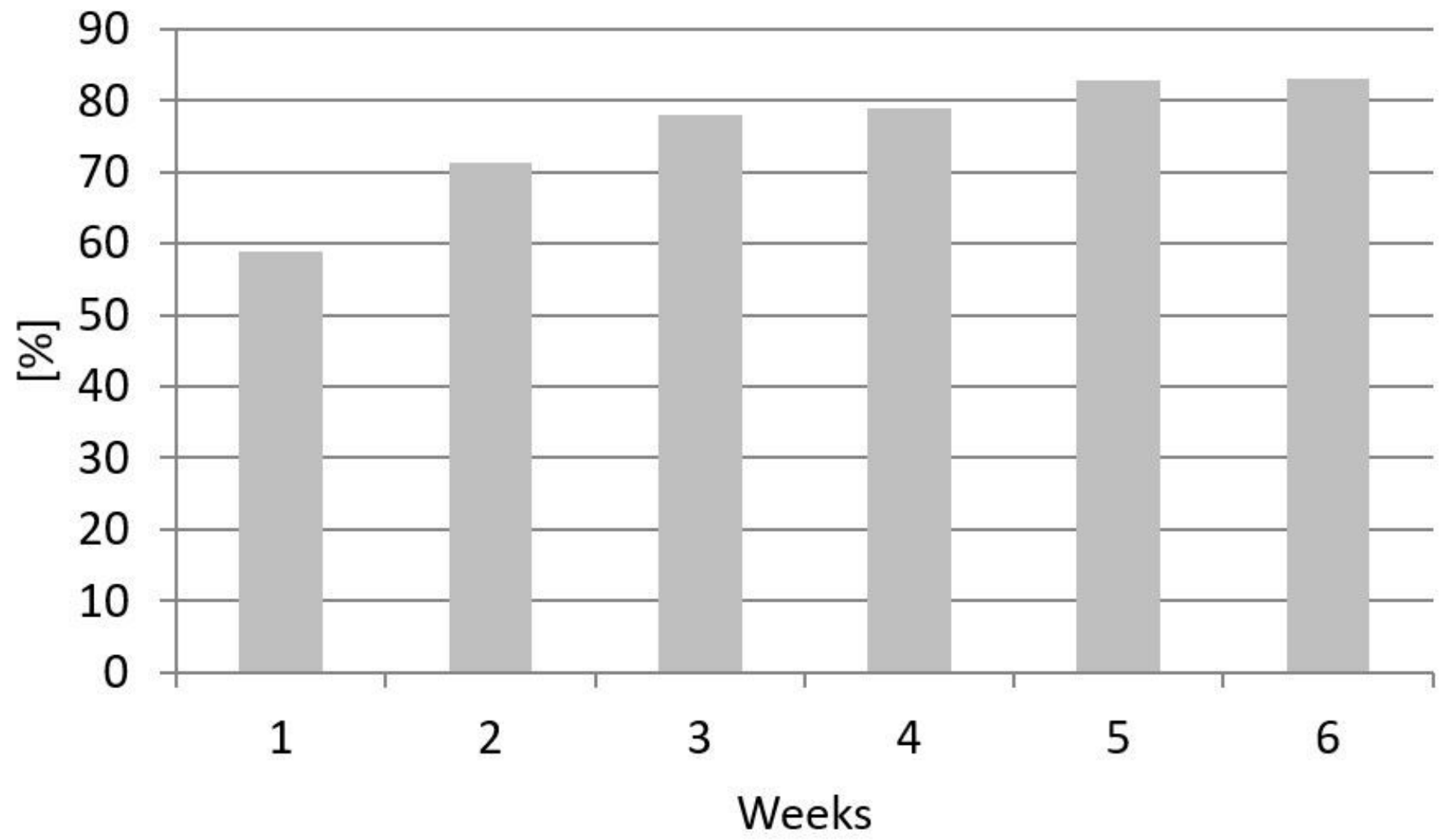


Figure 7

Decomposition rate of cooking oil during the experiment with PP.

\section{Supplementary Files}

This is a list of supplementary files associated with this preprint. Click to download.

- graphicsabtract.jpg 